Library Acquisitions: Practice \& Theory, 1986, Vol.10, i. 4, p.245-253.

ISSN: 0364-6408

http://www.sciencedirect.com/

http://www.sciencedirect.com/science/journal/03646408/10

http://dx.doi.org/10.1016/0364-6408(86)90027-X

(C) 1986 Pergamon Journals, Ltd.

\title{
THE GEAC ACQUISITIONS SYSTEM AS A SOURCE OF MANAGEMENT INFORMATION
}

\author{
CAROL P. HAWKS
}

\begin{abstract}
The University of Houston-University Park Libraries have been using the Geac Acquisitions System since September 1984. The system supplies management information in the areas of fund accounting, vendor performance, collection development, order control, and system management. Benefits, such as comprehensive versus summary reports, as well as shortcomings, such as length and paging of reports, were noted.
\end{abstract}

\section{INTRODUCTION}

To fully appreciate what I will say this morning, let me give you some additional background information about the University of Houston-University Park Libraries. University Park is the parent institution of a four-campus University of Houston system. The Libraries purchased the entire Geac Integrated Library System in September of 1982. The Online Catalog was brought online for the public in October of 1983. The Circulation System was implemented in May of 1984. The MARC Records Management System is in limited use now, with full implementation expected in the next 12 months.

Prior to the implementation of the Geac Acquisitions System, acquisition of firm orders was controlled by the batch computer-based system, BATAB. Therefore, our transition process was from batch to fully online, not manual to online. The Geac Acquisitions System was implemented at the beginning of our fiscal year, September of 1984. At that time, all ordering, receiving, claiming, and invoicing for monographs was begun. In addition, invoicing for all standing orders was started. The serials check-in subsystem was not implemented until January of 1986. The entire system is also used by our Law Library and the UH Downtown Library. All of the libraries share common files, but each agency's records are clearly identified and cannot be altered by another agency. Separate reports for each agency are generated by the system.

Our experience with the Geac Acquisitions System has been extremely favorable. We were among the first three large academic libraries to implement the full Acquisitions System, so we have been closely involved with the Geac programming staff and have had some influence in determining the direction that the system has taken. For example, we requested the programming of a specific report to deal with items which lacked sufficient information for transfer to the Online Catalog. That program was later added as a standard program in the system, and is known as the Houston Report.

Not the least of the benefits of automating acquisitions is the enhanced ability to monitor processes, to collect, structure, analyze, and report critical or useful data previously unavailable or 
extremely difficult or costly to obtain [1]. There can be little doubt that the more one knows, the better one can manage. The essence of good management is good information. In this sense, management as a function may be defined as interpretation of information so that appropriate decisions can be made [2]. In implementing the Geac system, we expected that the system would do more than simply track expenditures. Ideally, it would also act as a decision support system.

It would be a mistake to assume that management and the consequent need for management information applies only to the highest levels of administration. To some degree, management is a process at all levels of an organization [3]. Therefore, this presentation will focus on management implications of the Geac acquisitions system for 3 management levels - program managers, department heads, and upper level library administration.

Specifically, I will address five areas of management information generated within various components of the Geac Acquisitions System: fund accounting, vendor performance, collection management, order control, and system management (or how Geac looks at itself).

The management information provided by a system must be timely, appropriate, and comprehensive. My personal experience indicates that batch process systems are no longer capable of providing the right information at the right time. Effective management is dependent on effective reporting which provides a balance between summary and detail reports. The Geac system provides some comprehensive reports but it is the summary and exception reports coupled with the ability to inquire online which are the most useful management tools [4].

\section{FUND ACCOUNTING REPORTS}

Before entering the library marketplace, Geac was heavily involved in banking systems. This experience is particularly evident in the fund accounting reports of the Acquisitions system. "A properly designed accounting system provides for efficient accumulation, recording and reporting of data, assignment of authority and responsibility; and prevention of errors, fraud and waste. Accounting controls are designed to provide reasonable assurance of managerial control by incorporating four major control mechanisms into the overall accounting process. These include:

1) authorization by appropriate personnel of transactions or of access to assets;

2) transaction recording to allow for preparation of financial reports and for accountability of assets;

3) segregation of duties; and

4) monitoring of compliance."[5]

The Geac system is designed to accommodate the library's need for double bookkeeping. There are, in effect, two sets of accounting records: one for your parent accounting body, known within Geac as the financial services accounts, and one for your internal subject breakdowns, known as the budget asset accounts. This permits the library to support countless subject or format divisions while maintaining the general funds which reflect the actual accounts used by the institution's accounting department. The reports generated by the system reflect and report information for both sets of books.

In addition, the system will allow you to purchase titles on behalf of another fund. For example, you can process all approval invoices against a single budget asset fund. However, each title can also be credited to a specific department fund. Payment will not actually be made by the department fund, but records are maintained which indicate that the title was purchased on behalf 
of the department fund.

The system very carefully preserves the accounting principle of segregation of duties and accountability. The system permits access to its files only through use of security numbers which are individually assigned. Beyond this, each individual personnel record provides a set of privileges which can be set to Yes or No. For example, our reference librarians are given access to the system for informational purposes only. Nevertheless, they must sign on to the system with their name and security number. Once signed on, the system allows them display privileges in all files, but no update capabilities. Additionally, those staff members who process invoices have privileges for that activity but cannot order or receive titles. On the other hand, the system also provides the option of controlling these same privileges by terminal rather than by individual. For example, the privileges set for a particular terminal limit its use to a particular activity regardless of who has signed on to the system.

The fund accounting reports provided by the Geac system can be divided into six categories:
1) account information
2) payment information
3) currency conversion
4) invoice maintenance
5) standing order renewals
6) year end processing

The reports which deal with the financial standing of accounts offer a variety of options. There are two versions of each of these reports: one for the funds which actually paid for the title and one for the on behalf of funds mentioned earlier. The first of these reports (ABSAC1) creates a list of all the accounts and the financial standing of each. The figures included are the budget, amount committed or encumbered, amount spent, and the remaining balance. This report includes every account in the system. We generate this report every night, but it is also a report which can be run during the day when the online system is up.

The second report (ABSPOl) lists ail orders created within a specific time period (supplied by you) with accounting information about the orders. This report supplies the number of copies ordered, the amount committed or spent, and the fund. We have not found this report beneficial, since we utilize reports sorted by account number rather than order number.

The next report (ABBAC1) displays the standing of each account with respect to order type. Each title in the system is assigned an order type such as MONOGRAPH, APPROVAL, MONO SERIES, etc. Therefore, this report itemizes the amount spent and committed for the month and the year-to-date by type of material. This report is run on an "as needed" basis for us.

The next two reports (ABBGL1 and ABPUR1) emphasize the reporting of expenditures. The General Ledger report (ABBGL1) produces a list of journal entries and checks written against each account. It displays the debit and credit standings and the resulting account closing balance. The report is produced once a year. The purchase journal report is a very useful one for us. This report lists ail the payment vouchers issued in a specified time period, along with the invoices to which the vouchers are related. This report is run each Friday for the previous week. The report gives quick information on the amount expended by a specific fund for that week. One copy of this report is used by the library budget officer to record the date when each payment voucher is actually forwarded to Accounts Payable. 
There are two additional reports which deal specifically with the checks or payment vouchers generated by the system. The program which prints the actual payment vouchers also generates a check summary (ABCHQ1) which lists the voucher number, vendor, amount, and currency. Since we print these vouchers every day, this summary is kept with the vouchers until they are signed and forwarded to Accounts Payable. There is a second check register (ABCQR1) that can be generated which is much like the purchase journal report mentioned earlier. However, this register does not include the invoices covered by each voucher. We prefer the report which does include the invoice information.

The Geac system is well-equipped to deal with the long standing problem of accurate currency conversion. Each individual library establishes those foreign currencies which it wants to maintain in the system. A two- or three-letter code such as "UK" or "USA" identifies the currency and is assigned when the price is entered. For example, you can enter a unit cost of $30.00 \mathrm{UK}$ (or 30 pounds) and the system will automatically convert that to your base currency. Each week the currencies are updated in the system from The Wall Street Journal. Then an overnight program (ABUCUR) goes through the currency file and transfers the pending exchange rate into the current exchange rate. The system then reports the $+/$ - difference in each currency. At the same time, each encumbrance is recalculated at the new rate and the new figure is encumbered. A second report (ABCUR1) scans the orders and compiles the changes by order type and fund. Thus, you can see if the new exchange rates have increased or decreased the encumbrances on a particular fund.

There are a series of reports which focus on invoice maintenance. The invoice aging list (ABAGE) is used primarily by our Serials Department. This program creates a list using a given date (usually the date run) to compare against the invoice due date. The system ignores invoices marked as paid or cancelled. The report sorts invoices into one of three categories: less than 30 days, 30 to 60 days, or greater than 60 days. Because of state restrictions, we can pay for serial renewals no earlier than 6 weeks before their start date. Therefore, as soon as serial invoices are received, they are entered in Geac and held until they can be processed for payment. This report helps us keep track of those invoices as well as credits which have not yet been applied to invoices.

All invoices must be verified in the system before they are paid. In the process, the system checks each invoice line and the invoice as a whole. The system will prorate discounts, postage, handling charges, and taxes (if applicable) to each title or specified titles on each invoice. The verification process also checks to see that the vendor on the order and on the invoice are consistent, whether the title is missing receipts, or whether the number of copies and volumes matches. This process can be done online or in an overnight program (ABINV1). We prefer to perform this activity online except in cases where the invoice has over 500 individual lines. If an error is detected in the overnight program, the system reports the error message and does not verify the invoice. If no error is detected, the invoice is marked as verified.

Another invoicing report (ABPCI) is concerned with price increases. The report displays the difference between the price on the order and the price on the invoice. You enter a percent margin (that is, the minimum difference), and the program ignores any discrepancy less than that percentage. This program would be of particular use to libraries which require additional approvals when prices increase more than a defined percentage. Unfortunately, this program only deals with firm orders and not serials. This report can also be used for collection management purposes.

The final invoicing report is generated by the tape loading of serial invoices. Invoices can be supplied on tape to the library and the tape is then downloaded into the system. The first step of 
the process seeks to match the invoice lines with orders in the system. Therefore, the system purchase order number for each title must be conveyed to the vendor so that the purchase order number can be included on the tape. This first process generates a report which indicates such information as failure to locate the appropriate purchase order and price discrepancies (as in the previous report). Once these error conditions have been resolved, the invoice can actually be loaded into the system. Obviously, this can save days of data entry, particularly if a library's subscriptions with a single vendor number in the thousands. As of this date, only Faxon invoices can be loaded on Geac in this manner. The University Park campus will be doing the alpha testing for the loading of EBSCO tapes later this summer.

Projecting the cost of serial and standing order renewals has always been of particular concern to libraries. Nationwide studies can provide us with an average inflation rate but this average may be seriously inaccurate because of a library's particular mix of serials. The Geac System has a series of programs which have the potential for resolving this problem. The first report (ABREVW) produces a list of items with invoice history and a projected price based on an inflation rate set by the library.

After this report has been reviewed, a second program (ABREN1) is run which allows the renewals to be committed at the price projected by the first program, which then replaces the old estimated price for the title. The final report (ABREN3) produces a list of all the serial items that were renewed along with their estimated price.

After several years online, a library will be able to calculate their inflation rate as compared to the national average. A library must have at least 1 year of invoicing history before these programs can be used effectively. The University of Waterloo Library is currently working with Geac to evaluate and refine this process. One area of concern is the ability to exclude specific titles from this process on an individual basis. We will begin experimenting with this report in the near future.

The final category of fund accounting reports is the year-end processing reports. At the end of the library's fiscal year, the accounts must be closed. Expended funds are zeroed out and a final expenditure report is produced. In addition, the system must report on the status of unexpended funds. The first report (ABYRER) provides a summary of funds committed and carried forward, unspent and carried forward, and unspent but not carried forward at year-end. This report deals specifically with the dollar amounts and not the orders in the system. There are 2 reports which identify the orders which were carried forward. The first report (ABCFR1) provides details, on an account basis, of present commitments and spent amounts incurred since year end. The second report (ABCFR3) provides details, on a vendor basis, of present commitments and spent amounts incurred since year end. We produce these reports weekly, since we are allowed to carry money forward into the next fiscal year to pay for these encumbrances.

\section{VENDOR PERFORMANCE REPORTS}

Vendor performance reports are considered basic management information in most systems. The usefulness of vendor performance reports in renewing purchase orders and maintaining effective supply sources is significant. These reports attempt to answer the age-old question of which vendor delivers books fastest and with the greatest discount. The Geac system provides 4 vendor performance, reports to answer this question.

The first report (ABVEL1) is known as the "vendor performance by elapsed time" report. The report organizes the information according to the time difference between the date of order 
and the date of receipt. This provides you with an idea of how quickly each vendor ships orders. The report is broken down into time periods of 30 days each, such as less than 31, 32-61, more than 184, etc. Each time period includes the number of orders received and the percentage completed. The final figure is the average delivery time. The report is generated once a year, and the average delivery time is used to update our vendor files for claiming.

The vendor performance statistics report (ABVPR1) provides a number of statistics relating to each vendor. From this report, you can determine the dollar amount committed and spent with each vendor. (This information is also available online in an abbreviated form.) The number of orders placed and completed and the percent completed is provided. The average price per order is also included. In addition, the report shows the percentage of cancelled orders versus orders placed, the percentage of claims versus orders placed, and the count of single, double, and three or more claims.

The last two reports (ABVSTR and ABVSTS) provide information on vendor discounts one in great detail and the other in summary form. The first report lists all invoice lines that were entered between specified dates for each vendor. A report that lists every invoice line is an example of a report that cannot be successfully run in a large library such as University of Houston. Fortunately, in this case, Geac provides an alternative. The second report summarizes the information generated in the first report. This summary includes the amounts invoiced with the discounts and percentages. However, it should be noted that this report relies on accurate discount recording in the invoicing function. The only drawback to some of these reports is that they create a new page for each vendor. Our vendor file includes approximately 1700 vendors; therefore, each report is 1700 pages, which prohibits us from running them more than once a year.

In addition to vendor performance reports, Geac provides programs to generate various lists of vendors and their addresses. A single listing of all vendors (ABAVND) is available in addition to selected lists. The selected lists include blacklisted vendors (ABBVND) and exchange vendors (ABEVND). These lists can be very useful in maintaining and updating your vendor files.

\section{COLLECTION MANAGEMENT REPORTS}

Acquisitions does not operate in a vacuum. It is tightly coupled to collection development as well as cataloging and circulation [6]. The Geac system does generate some data to support collection development and resource management.

Geac facilitates the entry of order requests into the system by selectors outside of the Acquisitions Department. Acquisitions is notified of these requests each morning when the system generates printed search requests (ABREQ). These research requests include basic bibliographic information as well as selector and fund information, price and source, and other miscellaneous notes. The bottom of the request is reserved for searching tools which are library defined. These forms can then be used for verification activities. This report is also an excellent source for spot checking the accuracy of input into the system.

Although the system encourages request entry from outside the Acquisitions Department, we have modified the use of these reports to meet our specific needs. The implementation of the Geac system has resulted in a considerable increase in efficiency within the Acquisitions Department. Therefore, in addition to reducing staff, the Department has increased its responsibility in the area of request generation. Requests for purchase are entered directly into Geac by Acquisitions staff from publisher catalogs, flyers, or other sources received from subject selectors. This has eliminated the double keying of order information onto paper forms by 
selectors and then again into the system by Acquisitions staff. Whether titles are entered by selectors or Acquisitions staff, this report reduces the amount of double keying required.

The system provides a number of useful reports for subject selectors. There are a series of reports (ABAPO?) which record activity on a particular fund. The one we use most frequently is the Agency Open Order Report (ABAPO5). This report provides a summary of orders which have been active within a given time period. The report extracts purchase orders that have been created, cancelled, invoiced, or received during the time specified. There are also reports that reflect a single activity such as receipts or claims instead of the combined listing. We provide this combined listing to our selectors bimonthly. They also receive monthly and quarterly summaries to avoid searching multiple alphabetical listings. These reports were used heavily during initial implementation of the system, but experience has given way to more dependence on the online system for up-to-date information.

The system also produces a fund accounting report (ABSAC2) specifically designed for subject selectors. It reports budget allocation, amount committed, amount spent, and free balance. The report's most useful asset is that it prints individual subject accounts on separate pages so that the report can be easily separated and sent to the appropriate subject selector.

The Desiderata report produces a list of requests that have been flagged as desiderata in the system. This report sorts by account number. Therefore, if your accounts reflect a subject allocation, your desiderata requests will be sorted by subject. We use this report to build a desiderata file for expending excess funds at the end of our fiscal year, or for release at the beginning of the new fiscal year. The University of Waterloo has plans to use this report to generate lists of out-of-print titles to be sent to specialized dealers.

The system supports two programs (ABORDN and ABORRN) which provide notification information for titles on order. The first (ABORDN) lists orders that have been flagged for a status of NOTIFY WHEN ORDERED. The second (ABORRN) lists orders that have been received and have the NOTIFY WHEN RECEIVED status flag set. There are two drawbacks to these reports which have precluded our use of them. The system will only accept the names of people who have been entered in the staff function of the system. Secondly, this notify information is generated in report form and cannot be attached to the individual piece. However, in the next release, this information will be printed on the routing slip which is inserted in each book and kept with the title throughout cataloging. Thus, faculty who routinely request books will be entered in the file initially and others will be added as needed.

Another interesting report is the Order Type Report (ABTIL1). This report produces a list of titles selected based on their order type. Princeton has used this report to generate a list of all its monograph series on standing order. The list was then reproduced on microfiche and is used for collection development and for approval profiling.

The final collection management report has been very useful for the University Park campus. This report is an alphabetical list of all current serial subscriptions with allocated amount, frequency type, and vendor information by fund. Prior to the implementation of Geac, we could not generate a comprehensive list of serial subscriptions by fund. This report has been an invaluable tool in evaluating our current serial subscriptions. The lists can be sent to faculty members as well. A price-ordered list (high to low) would also be useful for collection development but does not exist.

There are a number of interesting reports which do not fit any of the earlier categories but which cannot be overlooked. For example, there is a series of reports known as exception reports which report items which have remained too long in a particular stage such as invoicing. Detecting 
and handling exceptions is normally a 3-step process. First, an extract program examines the entire database and identifies items requiring action, such as a title that has not been received by its estimated delivery date. Second, an exception report lists the item and the required action. Finally, staff initiate whatever action is required. There are five of these exception reports. They report requests that have not been ordered, orders that have not been received, claims that have not been answered, receipts that have not been invoiced, and invoices that have not been paid. The only report not provided is an overdue in cataloging report. Fortunately, the University of Houston Bibliographic Control Department has a turnaround time of approximately two weeks and no backlog.

For those libraries which prefer automatic cancellation of specified orders, Geac can now provide appropriate programs. The first of these programs (ABCANA) is for informational purposes only. It produces a list of titles which fit the criteria set in the program. These include vendor, order type, and number of days on order without receipt. This report is run first so that the library can be sure that it intends to cancel these titles, since cancellations are irreversible in the Geac system. The second report (ABCANB) actually cancels the orders and produces cancellation letters.

For serials which require binding, the system can produce a binding list (ABBND1). This list operates from the serials check-in system, and the system must be operational for several months before this procedure is applicable. The report notifies the library when the final issue of a volume for a particular serial has been received. The report can then be used to collect the issues for binding.

I referred to a report earlier which has been titled the Houston Report (ABSTYP). This program scans the Acquisitions database to identify items on order which do not contain adequate bibliographic information to transfer to the Online Catalog. It lists items that do not include an ISN, LCCN, or Geac Record Sequence Number (GRSN) in the record. Usually these items will be serials. Since we will eventually transfer on-order titles and serial receipts directly to the online catalog, this report will allow us to establish the appropriate links between serial records in the Online Catalog and in the Acquisitions database before this process begins.

\section{SYSTEM MANAGEMENT REPORTS}

System management reports (or utilities) provide information on the system itself. These reports are not designed for the computer operations manager but rather for the librarian responsible for the management of the Acquisitions System. The first of these (APTRSH) reports the number of times the send key was pressed at each terminal. This information is useful for determining the usage of particular terminals and indicates whether the placement of terminals is appropriate. This program also reports the reset statistics by terminal. A reset indicates that you have cancelled a screen display and have returned to the general menu. Such resets occur most often when the operator does not know what to do next. Therefore, these statistics are particularly useful during initial system implementation, the training of new staff, and when new sites (such as branches) are brought onto the system.

The second report (APFCHK) provides statistics for each file in the system, including the

number of orders, vendors, and invoices. In addition, this report reflects the amount of space left in each of these files. This report has been of particular interest to our library. Since our online files are filling rapidly, it is important that we monitor their growth with this report. Geac plans to implement its history file in late 1986. This file will help alleviate this problem by permitting 
cancelled or completed orders of a certain age to be purged from the online system and recorded on magnetic tape.

One thing to remember about the various reports I have mentioned is that local policy, database size, and long hours of operation can hamper full utilization of some Geac reports. Some reports can be run more reasonably at a smaller institution with a smaller database. The size of our library prohibits use of some cumulative reports which might be useful but which require too much time and computer memory to run. A wealth of information is available. Finding time to use it all, however, is another matter [7]. "As most information managers recognize, however, the very ease with which elegant compilations of all kinds can be produced may encourage excesses in reporting" [8].

In conclusion, automated acquisitions systems can provide us with excellent management information. However, in your Request for Proposal or RFP, be sure to ask for the obvious. Do not assume that a vendor will provide reports that you, as a librarian, see as essential.

\section{REFERENCES}

1. Kennedy, Robert. "Computer-derived Management Information in a Special Library," in Clinic on Library Applications of Data Processing, University of Illinois. Proceedings:

Library Automation as a Source of Management Information. Urbana-Champaign, IL: University of Illinois, Graduate School of Library and Information Science, 1982. p. 128.

2. Bruer, J. Michael, "Management Information Aspects of Automated Acquisitions Systems," Library Resources and Technical Services 24, 4 (Fall 1980): 339.

3. Bruer, "Management Information Aspects," p. 339.

4. Bruer, "Management Information Aspects," p. 340.

5. Begg, Robert T. "Internal Control Systems in the Library Environment," Journal of Academic Librarianship. 10, 6: 339.

6. Bruer, "Management Information Aspects," p. 342.

7. Mullin, Wayne. "Geac as a Source of Management Information," in Clinic on Library Applications of Data Processing, University of Illinois. Proceedings: Library Automation as a Source of Management Information. Urbana-Champaign, IL: University of Illinois, Graduate School of Library and Information Science, 1982, pp.75, 85-6.

8. Kennedy, "Computer-derived Management Information," pp. 145-7, 